\title{
Pain in preterm newborns submitted to music and $25 \%$ glucose intervention
}

\author{
Dor em recém-nascidos pré-termo submetidos à intervenção música e glicose $25 \%$
}

Gleicia Martins de Melo ${ }^{1}$, Maria Vera Lúcia Moreira Leitão Cardoso ${ }^{1}$

Objective: to compare the pain response of preterm newborns submitted to arterial puncture who received musical intervention with those who received 25\% glucose intervention. Methods: randomized, double-blind clinical trial; the sample consisted of 48 videos of preterm infants of the experimental group (music, $n=6$ ), who listened to music for 10 minutes, and the control group (25\% glucose, $n=22$ ), who received $25 \%$ glucose two minutes before puncture. The pain was evaluated by the Neonatal Facial Coding System at moments: Baseline, Treatment, Painful, Recovery 1 and Recovery 2. Results: there were similarities between groups at the moments Baseline, Recovery 1 and 2. A statistically significant difference was observed at the moment Treatment $(\mathrm{p}=0.014)$, Painful $(\mathrm{p}=0.029)$ for the control group. Conclusion: $25 \%$ glucose differed from music when comparing the pain response in the Treatment and Painful moments. Brazilian Registry of Clinical Trials: UTN: U1111-1123-4821.

Descriptors: Infant, Newborn; Pain; Music; Glucose; Intensive Care, Neonatal; Neonatal Nursing.

Objetivo: comparar resposta de dor de recém-nascidos pré-termo submetidos à punção arterial que receberam intervenção musical com os que receberam intervenção de glicose 25\%. Métodos: ensaio clínico randomizado, duplo cego, amostra de 48 vídeos de prematuros dos grupos, Experimental (música, n=26), ouviu música por 10 minutos e; Controle (glicose $25 \%, n=22$ ), recebeu glicose $25 \%$ dois minutos antes da punção. A dor foi avaliada pela Neonatal Facial Coding System nos momentos: Basal, Tratamento, Doloroso, Recuperação 1 e Recuperação 2. Resultados: houve semelhanças entre grupos nos momentos Basal, Recuperação 1 e 2. Constatou-se diferença estatisticamente significante no momento Tratamento $(\mathrm{p}=0,014)$, Doloroso $(\mathrm{p}=0,029)$ para grupo Controle. Conclusão: glicose $25 \%$ diferiu da música ao se comparar a resposta de dor nos momentos Tratamento e Doloroso. Registro Brasileiro de Ensaio Clínico: UTN: U1111-1123-4821.

Descritores: Recém-Nascido; Dor; Música; Glucose; Terapia Intensiva Neonatal; Enfermagem Neonatal.

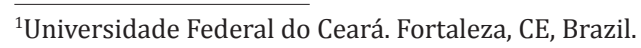




\section{Introduction}

Preterm infants admitted to the Neonatal Intensive Care Unit are likely to experience various painful and stressful procedures ${ }^{(1)}$. It is estimated that they undergo on average 12 painful procedures per day ${ }^{(2)}$, which can be modified according to the clinical state, length of hospital stay and exposure to external stimuli, such as intense and continuous light, ambient temperature and noises ${ }^{(3)}$. The arterial puncture for the collection of exams ${ }^{(4)}$ is one of the most common, which refers to acute pain for the neonate.

The use of instruments for the measurement of acute pain in newborns is indispensable, among which the scales stand out because they have precise and valid characteristics when identified through serious and in-depth studies. The evaluation of pain by the behavioral parameters is considered pertinent in clinical practice, specifically by facial mime, through the Neonatal Facial Coding System (NFCS). When considering facial mime, these behavioral reactions have increased importance, once it is a tool used in human communication that makes possible identifying feelings and ideas ${ }^{(5)}$.

For this study, the evaluation of facial mime at the moments Baseline (in which the preterm newborns were kept at rest, without interventions, inside the heated crib or incubator before the arterial puncture), Treatment (submitted to antisepsis for arterial puncture), Painful (after needle insertion for puncture), Recovery 1 (cotton compression after collection of arterial puncture), and Recovery 2 (resting of premature infants upon completion of compression).

Technological advances have increasingly enabled the survival of very premature or very sick infants ${ }^{(6)}$. In the context of nursing care, non-pharmacological measures are highlighted as a strategy of care for pain relief, such as the use of music ${ }^{(4,7)}$ and $25 \%$ glucose ${ }^{(8)}$.

Using music in newborns promotes relaxation $^{(9-10)}$, diminishes anxiety and pain perception, alters moods and promotes distraction and comfort ${ }^{(10)}$.
On the other hand, the use of glucose solution ${ }^{(9)}$ releases endogenous endorphins, decreases crying and attenuates facial pain mime ${ }^{(11)}$.

In view of the above, the following question emerged as a guideline for the development of this study: what is the effect of music and $25 \%$ glucose in preterm newborns submitted to arterial puncture for the collection of exams according to the NFCS scale? In this context, we aimed to compare the pain response of preterm newborns submitted to arterial puncture who received musical intervention with those who received $25 \%$ glucose intervention.

\section{Methods}

Randomized, double-blind clinical trial linked to the filming database of a doctoral thesis ${ }^{(4)}$. For the blinding, the nurses who did the filming analysis and the person in charge of the statistical analysis were not aware of the group and of the intervention administered in the premature infant, so the study was protected from detection bias.

The research was carried out at the Neonatal Unit of a Public Hospital of Fortaleza, Ceará, Brazil. A number of 66 premature infants was estimated by using the sample size formula for experiments in comparison to unpaired groups, $\alpha=0.05$ and estimated power at $80.0 \%$. Considering the possibility of losses after randomization, a larger total number was estimated, totaling $20.0 \%$ more than expected. So, it would be necessary to carry out the study with 80 newborns. The infants were organized in Experimental Group 1 (music), Experimental Group 2 (music and glucose 25\%) and Positive Control Group (25\%glucose).

The inclusion criteria were: preterm newborns with need for arterial puncture for collection of exams as part of their clinical treatment; gestational age $\geq 32$ weeks and <37 weeks; Apgar $\geq 6$ in the 5th minute; clinically stable with heart rate (120 to $140 \mathrm{bpm}$ ) and respiratory rate (40 to 60 incursions per minute); normal hearing neonatal screening test; in any type of 
support for oxygen therapy.

The collection took place from May to August 2013 with selection of 55 filming records linked to the filming database, participating of the music and 25\% glucose groups. The sample consisted of 48 videos, 26 were selected in the Experimental Group (music); and 22 in the Control Group (25\% glucose), respecting the criterion that the neonates' faces could be analyzed, without detriment to visualization. Recordings with difficult face-visualization and synchronization problems were excluded.

All premature infants used headphones, however, only those from the Experimental Group received a single instrumental lullaby from the Happy Baby collection of the recording company Atração Fonográfica $L t d a$, produced especially for newborns. The song was played during 10 minutes after the Baseline moment and before antisepsis for arterial puncture (Treatment moment) by using a MP4 device, positioned outside the incubator, at a volume of 40 decibels. $25 \%$ oral glucose was administered immediately two minutes before the Treatment moment, in a syringe, by means of gauze strip.

The instruments used in the collection were the NFCS pain scale and the script for surveying the neonatal variables that were extracted from the database, based on the information obtained by consulting the medical records of the preterm infants hospitalized at the Neonatal Unit.

The scale comprises the presence or absence of five facial manifestations, according to the Training Handbook $^{(12)}$, as follows: bulging forehead, tight eyes, deepened nasolabial fold, open mouth horizontally and tense tongue. For each manifestation of facial mime in the observed period, that is, in two seconds, a point was scored.

The NFCS was used to capture the facial mime of the newborns at moments Baseline, Treatment, Painful, Recovery 1 and Recovery 2. At the moments Painful and Recovery 1, infants were evaluated during the initial 20 seconds. For the moment Recovery 2, we considered the final 20 seconds of the five min- utes, since the beginning of the moment Recovery 1 . So, for each of these moments, ten facial mime evaluations were obtained, in the 20 seconds. Regarding the moments Baseline and Treatment, it was not possible to maintain the 20 seconds of NFCS evaluation, being necessary to do an adaptation in the scale, as in the Baseline moment, eleven filming records had time less than 20 seconds and at the moment of Treatment the antisepsis was performed in a very brief period, which included the beginning of the Painful moment. Therefore, with the purpose of standardizing the time in these two moments for all the filming records, we opted for the analysis of 14 initial seconds for the Baseline moment and four final seconds for the moment of Treatment.

Referring to the Baseline moment, it should be noted that the preterm newborns of the Experimental Group and the Control Group were filmed without manipulation and administration of non-pharmacological interventions.

The facial mime of the premature newborn was obtained by means of two digital cameras, placed in a tripod. The first camera was directed towards the face of the newborn, at a distance of $30 \mathrm{~cm}$. The second one was positioned at a distance of $60 \mathrm{~cm}$ from the preterm newborn and aimed to film the painful procedure.

One of the authors of the study separated and watched all the DVDs to record the real time of the beginning and the end of each moment investigated. Three nurses, specialists in Neonatology, were selected to participate in the analysis of the filming records after the training of the NFCS scale performed by a pain expert. The evaluators were considered able to carry out the evaluation after the Kappa reliability reached at least $80.0 \%$.

Initially, the database was structured in an Excel spreadsheet to encode the variables, and double-typing was performed to ensure the reliability of the data. The data were exported to the software Statistical Package for the Social Sciences (version 19.0). The analysis of the effect of interventions on 
pain scores was performed by using generalized linear models with repeated measures, followed by the Bonferoni test. It was considered a significance level of $5 \%$ for all tests $(\mathrm{p}<0.05)$.

The study complied with the formal requirements contained in the national and international regulatory standards for research involving human beings.

\section{Results}

From the 48 filming records of preterm newborns, there was prevalence of males, gestational age corrected in weeks between 32 and 36.6; at the moment of the arterial puncture the chronological age (days) was found between the first day of life (12h) and 40 days, for both groups. In the experimental group, the birth weight was $2.136 \mathrm{~g}$, the Apgar index in the $5^{\text {th }}$ minute was 8.5 . For the control group, data were $1.868 \mathrm{~g}$ and 8.3 , respectively.
Figure 1 shows the large variability of the NFCS weighted score at all times of collection for both groups. Some premature infants outside the interquartile range (outliers) were also identified, especially at Baseline and Recovery 2 moments. The presence of outliers was also observed in the Control Group, at the Treatment moment.

When quantitatively evaluating the scale over time, at the moment Treatment, a statistically significant difference was observed between the means of the Experimental Group and the Control Group (difEGCG $=2.1 \mathrm{p}=0.014)$. In the Painful moment, $\mathrm{a}$ statistically significant difference ( $\operatorname{dif}=2.0 ; \mathrm{p}=0.029$ ) was observed between the two groups, with the mean of weighted NFCS of the Experimental Group (music) being higher than that of the Control Group (25\%glucose) (Table 1).

The moments Recovery 1 and 2 presented in a similar way, with no statistical difference between the two groups (Experimental and Control) (Table 2).

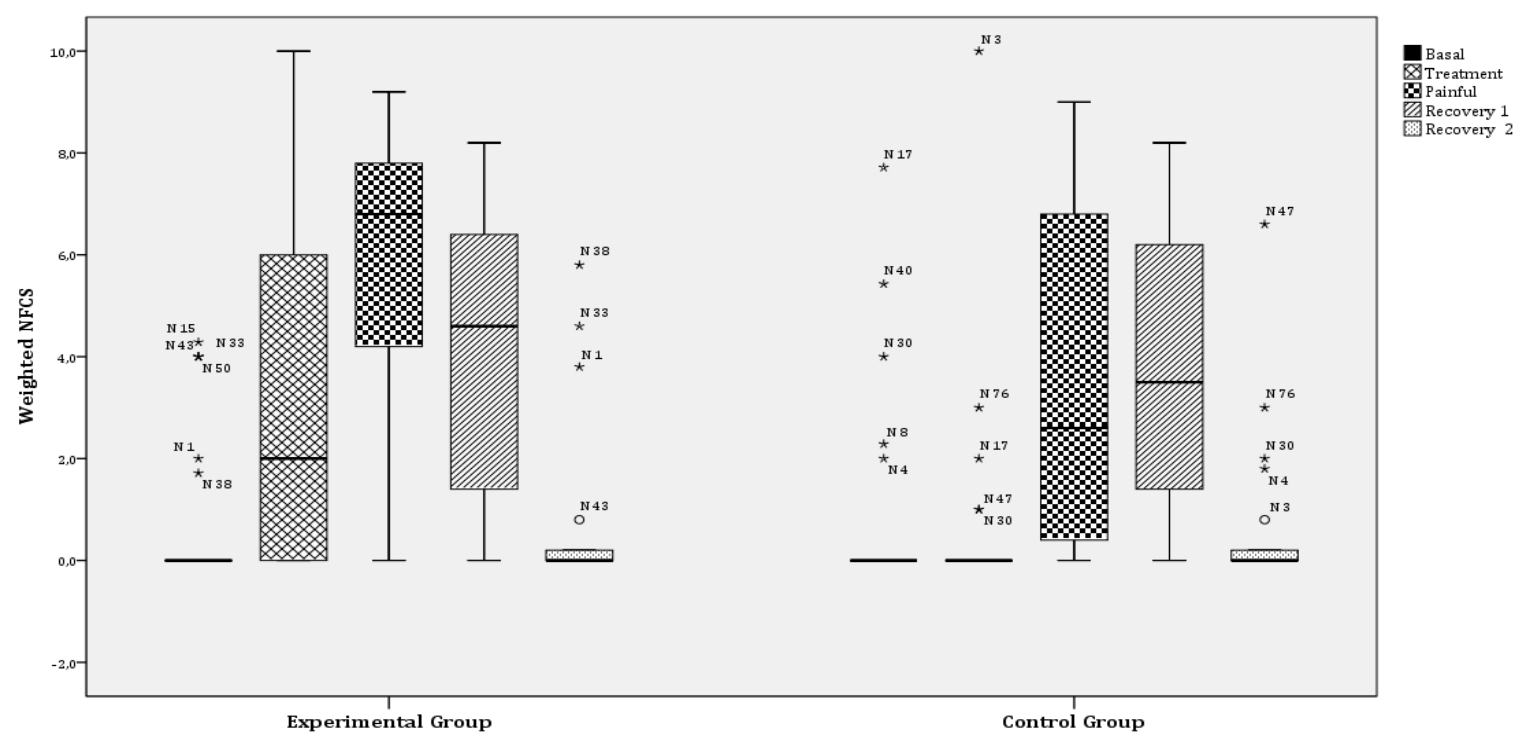

Figure 1 - Distribution of median values, interquartile range, minimum and maximum values of the standardized scores of facial activities of the NFCS scale in each intervention group, according to collection periods 
Table 1 - Mean score, standard deviation, confidence intervals and comparison test of means for the moments Treatment and Painful of preterm newborns according to the allocation groups and time intervals

\begin{tabular}{|c|c|c|c|c|c|c|c|c|c|c|}
\hline \multirow{3}{*}{ Time intervals } & \multicolumn{4}{|c|}{ Experimental Group } & \multicolumn{4}{|c|}{ Control Group } & \multirow{2}{*}{\multicolumn{2}{|c|}{$\begin{array}{c}\text { Equality of } \\
\text { variances }\end{array}$}} \\
\hline & \multirow[t]{2}{*}{$\mathbf{X}^{1}$} & \multirow[t]{2}{*}{$\mathbf{S D}^{2}$} & \multicolumn{2}{|c|}{$\begin{array}{l}\text { 95\% Confidence } \\
\text { Interval }\end{array}$} & \multirow[t]{2}{*}{$\mathbf{X}$} & \multirow[t]{2}{*}{ SD } & \multicolumn{2}{|c|}{$\begin{array}{l}\text { 95\% Confidence } \\
\text { Interval }\end{array}$} & & \\
\hline & & & $\mathbf{I L}^{3}$ & $\mathbf{S L}^{4}$ & & & IL & SL & $\mathbf{F}^{5}$ & p-value ${ }^{6}$ \\
\hline \multicolumn{11}{|c|}{ Treatment Moment } \\
\hline $0-2$ & 2.8 & 0.6 & 1.7 & 4.0 & 0.6 & 0.6 & -0.6 & 1.9 & 14.7 & $<0.001$ \\
\hline $2-4$ & 3.0 & 0.6 & 1.8 & 4.2 & 0.9 & 0.6 & -0.4 & 2.2 & 7.4 & 0.009 \\
\hline Total & 2.9 & 0.6 & 1.8 & 4.1 & 0.8 & 0.6 & -0.5 & 2.0 & 2.1 & 0.014 \\
\hline \multicolumn{11}{|l|}{ Painful Moment } \\
\hline $0-2$ & 4.6 & 0.7 & 3.2 & 6.1 & 2.5 & 0.8 & 1.0 & 4.1 & 0.5 & 0.483 \\
\hline $2-4$ & 5.6 & 0.8 & 4.1 & 7.2 & 3.5 & 0.8 & 1.8 & 5.1 & 0.3 & 0.604 \\
\hline $4-6$ & 6.2 & 0.7 & 4.7 & 7.6 & 3.5 & 0.8 & 1.9 & 5.1 & 0.9 & 0.345 \\
\hline $6-8$ & 6.2 & 0.7 & 4.8 & 7.7 & 3.1 & 0.8 & 1.5 & 4.6 & 0.2 & 0.655 \\
\hline $8-10$ & 5.8 & 0.7 & 4.4 & 7.3 & 3.6 & 0.8 & 2.0 & 5.3 & 0.6 & 0.440 \\
\hline $10-12$ & 5.8 & 0.7 & 4.4 & 7.3 & 3.9 & 0.8 & 2.4 & 5.5 & 0.7 & 0.411 \\
\hline $12-14$ & 5.4 & 0.7 & 3.9 & 6.8 & 4.2 & 0.8 & 2.6 & 5.7 & 1.2 & 0.281 \\
\hline $14-16$ & 5.4 & 0.7 & 3.9 & 6.9 & 4.1 & 0.8 & 2.5 & 5.7 & 1.1 & 0.296 \\
\hline $16-18$ & 5.5 & 0.7 & 4.1 & 7.0 & 3.7 & 0.8 & 2.2 & 5.3 & 0.0 & 0.930 \\
\hline $18-20$ & 5.6 & 0.7 & 4.1 & 7.1 & 3.8 & 0.8 & 2.2 & 5.4 & 0.1 & 0.804 \\
\hline Total & 5.6 & 0.6 & 4.4 & 6.9 & 3.6 & 0.7 & 2.3 & 4.9 & 2.0 & 0.029 \\
\hline
\end{tabular}

Table 2 - Mean score, standard deviation, confidence intervals and means comparison test for the moment Recovery 1 and 2 of the preterm newborns, according to the allocation groups and time intervals

\begin{tabular}{|c|c|c|c|c|c|c|c|c|c|c|}
\hline \multirow{3}{*}{ Time intervals } & \multicolumn{4}{|c|}{ Experimental Group } & \multicolumn{4}{|c|}{ Control Group } & \multirow{2}{*}{\multicolumn{2}{|c|}{$\begin{array}{c}\text { Equality of } \\
\text { variances }\end{array}$}} \\
\hline & \multirow[t]{2}{*}{$\mathbf{X}^{1}$} & \multirow[t]{2}{*}{$\mathbf{S D}^{2}$} & \multicolumn{2}{|c|}{$\begin{array}{l}\text { 95\% Confidence } \\
\text { Interval }\end{array}$} & \multirow[t]{2}{*}{$\mathbf{X}$} & \multirow[t]{2}{*}{ SD } & \multicolumn{2}{|c|}{$\begin{array}{l}\text { 95\% Confidence } \\
\text { Interval }\end{array}$} & & \\
\hline & & & $\mathrm{IL}^{3}$ & $S^{4}{ }^{4}$ & & & IL & SL & $\mathbf{F}^{5}$ & p-value ${ }^{6}$ \\
\hline \multicolumn{11}{|c|}{ Moment Recovery 1} \\
\hline $0-2$ & 4.2 & 0.8 & 2.7 & 5.8 & 4.2 & 0.8 & 2.5 & 5.9 & 0.8 & 0.382 \\
\hline $2-4$ & 4.5 & 0.7 & 3.0 & 6.0 & 4.3 & 0.8 & 2.7 & 5.9 & 0.4 & 0.518 \\
\hline $4-6$ & 4.6 & 0.7 & 3.1 & 6.1 & 4.3 & 0.8 & 2.7 & 5.9 & 0.4 & 0.550 \\
\hline $6-8$ & 4.5 & 0.7 & 3.1 & 6.0 & 3.7 & 0.8 & 2.2 & 5.3 & 0.1 & 0.769 \\
\hline $8-10$ & 3.9 & 0.7 & 2.4 & 5.4 & 3.9 & 0.8 & 2.3 & 5.5 & 4.4 & 0.040 \\
\hline $10-12$ & 3.6 & 0.8 & 2.1 & 5.1 & 3.6 & 0.8 & 2.0 & 5.3 & 0.6 & 0.438 \\
\hline $12-14$ & 3.5 & 0.7 & 2.1 & 5.0 & 3.1 & 0.8 & 1.5 & 4.7 & 0.8 & 0.373 \\
\hline $14-16$ & 3.8 & 0.7 & 2.4 & 5.2 & 2.9 & 0.8 & 1.4 & 4.4 & 0.5 & 0.478 \\
\hline $16-18$ & 3.9 & 0.7 & 2.5 & 5.4 & 2.9 & 0.8 & 1.3 & 4.5 & 0.1 & 0.740 \\
\hline $18-20$ & 3.8 & 0.7 & 2.4 & 5.3 & 3.0 & 0.8 & 1.4 & 4.6 & 0.1 & 0.793 \\
\hline Total & 4.1 & 0.7 & 2.7 & 5.4 & 3.6 & 0.7 & 2.1 & 5.1 & 0.463 & 0.646 \\
\hline \multicolumn{11}{|c|}{ Moment Recovery 2} \\
\hline $0-2$ & 0.6 & 0.4 & -0.1 & 1.4 & 0.7 & 0.4 & -0.1 & 1.6 & 0.2 & 0.630 \\
\hline $2-4$ & 0.7 & 0.4 & -0.1 & 1.5 & 0.7 & 0.4 & -0.1 & 1.6 & 0.0 & 0.851 \\
\hline $4-6$ & 0.7 & 0.4 & -0.1 & 1.5 & 0.7 & 0.4 & -0.1 & 1.6 & 0.0 & 0.851 \\
\hline $6-8$ & 0.5 & 0.3 & -0.1 & 1.2 & 0.6 & 0.4 & -0.1 & 1.4 & 0.1 & 0.712 \\
\hline $8-10$ & 0.5 & 0.4 & -0.3 & 1.2 & 0.7 & 0.4 & 0.0 & 1.5 & 1.1 & 0.306 \\
\hline $10-12$ & 0.6 & 0.4 & -0.2 & 1.4 & 1.0 & 0.4 & 0.1 & 1.9 & 1.4 & 0.237 \\
\hline $12-14$ & 0.7 & 0.4 & -0.1 & 1.4 & 0.5 & 0.4 & -0.4 & 1.3 & 0.8 & 0.385 \\
\hline $14-16$ & 0.5 & 0.3 & -0.1 & 1.2 & 0.5 & 0.3 & -0.2 & 1.2 & 0.1 & 0.750 \\
\hline $16-18$ & 0.5 & 0.3 & -0.2 & 1.2 & 0.5 & 0.4 & -0.2 & 1.3 & 0.2 & 0.685 \\
\hline $18-20$ & 0.5 & 0.4 & -0.2 & 1.3 & 0.5 & 0.4 & -0.2 & 1.3 & 0.0 & 0.932 \\
\hline Total & 0.6 & 0.3 & -0.1 & 1.3 & 0.7 & 0.4 & -0.1 & 1.4 & -0.07 & 0.891 \\
\hline
\end{tabular}




\section{Discussion}

This study presents as limitations the administration of a single music time in premature infants undergoing arterial puncture.

Authors aimed to investigate the effect of music in comparison to $25 \%$ glucose for pain relief in preterm newborns submitted to arterial puncture through facial manifestations of NFCS, however, there are still few studies that investigate such interventions in the arterial puncture. The main finding was that the preterm newborns in the music and $25 \%$ glucose group, when evaluated by the standardized scores of the NFCS, in moments Recovery 1 and 2, presented similar pain scores when submitted to arterial puncture, that is, the effect of interaction between time and intervention was not statistically significant at these two moments after the Painful moment.

A clinical trial comparing the effect of $10 \%$ glucose $(2 \mathrm{ml}$ two minutes before the painful calcaneal puncture) and of music (every 5 minutes for a maximum time of 20 minutes before the painful procedure) with the control group (without intervention) in 105 premature infants admitted to the Neonatal Intensive Care Unit identified through the Premature Infant Pain Profile that 10\% glucose and music are safe and effective in relieving newborns' pain when compared to the control group. The mean increase in the Premature Infant Pain Profile was 3 points in the control group (IQR 2-6), 1 point in the 10\%glucose group (IQR 0-2), and 2 points in the music group (IQR 1-4), with $\mathrm{p}=0.008^{(13)}$.

A randomized clinical trial with 80 preterm newborns analyzed the total scores of the Premature Infant Pain Profile of premature infants undergoing arterial puncture under music intervention (Experimental Group 1), music and 25\% glucose (Experimental Group 2) and 25\% glucose (Positive Control Group). It was observed that in $60.0 \%$ of the premature infants who presented moderate or severe pain there was no statistically significant association $(\mathrm{p}=0.398)$ between the pain score category and the intervention groups ${ }^{(4)}$.

It is necessary to mention that the behavioral responses of greater activation were observed in the Treatment and Painful moments, for the newborns of the Experimental Group, as well as in the Painful and Recovery 1 moments for those allocated in the Control Group, with statistically significant differences at the Treatment moment and at the Painful moment in favor of the control group (Table 1).

Although the mechanism of administration of sweetened solutions is not yet fully understood, the use of these measures involves the activation of the endogenous opioid system ${ }^{(7)}$ by the palate. Successive glucose administrations result in the phenomenon of tolerance and decrease of the expected analgesic effect, being observed, in the initial phase of hospitalization of the newborns, a more pronounced effect of analgesia ${ }^{(14)}$, thus justifying the analgesic effect of sweetened solutions, as $25 \%$ glucose, in the preterm infants allocated to the Control Group.

It should be noted that, in the Control Group, the Treatment moment (antisepsis) was the first interval, measured shortly after the preterm infants received $2 \mathrm{ml}$ of $25 \%$ glucose, two minutes before the painful puncture procedure. It should be noted that, at this time, the difference of means with statistically significant $\mathrm{p}$ (difEGCG $=2.1 \mathrm{p}=0.014$ ) for the $25 \%$ glucose group seems to be related to the initiation of the effect of the sweetened solution on the palate of premature infants, as the values differed during the evaluated moments.

At the moment Recovery 1, the groups had a similar behavior, with no statistical difference between them (dif $=0.463, p=0.646$ ). There was a mean reduction of the weighted NFCS of the Experimental Group ( $4.1 \pm 0.7)$ in comparison with the Painful moment $(5.6 \pm 0.6)$ and with means of equal values in the Control Group (3.6 $\pm 0,7)$.

In a clinical trial of 113 newborns, randomized to receive $2 \mathrm{ml}$ of milked maternal milk (experimental group) and $2 \mathrm{ml}$ of $25 \%$ glucose (control group) given 
2 minutes before calcaneal puncture for pain relief, the scores of Premature Infant Pain Profile were significantly lower $(\mathrm{p}<0.02)$ in the group receiving $25 \%$ glucose, compared to the group that received breast milk. There was a lower incidence of crying $(p=0.001)$ and shorter crying duration $(\mathrm{p}=0.014)$ for newborns in the Control group ${ }^{(8)}$.

In the intervention in the experimental group, in which the preterm newborns were under the effect of music for 10 minutes, it was observed, at the moment of Treatment, when performing manipulation to carry out the antisepsis, as well as in the Painful moment, during the needle insertion for arterial puncture, a statistically significant $p$ in favor of the Control Group. This result may be related to the time it takes for music to act as a non-pharmacological measure in the behavioral reactivity of the newborn, since, over time, there was a decrease in the mean in all newborns allocated with music in the moments Recovery 1 and 2.

It is worth noting that there is still no consensus on the ideal duration of music with a therapeutic purpose of pain relief in preterm newborns. Some scholars have adopted 6 minutes $^{(15)}, 12$ minutes $^{(16)}$ and 20 minutes ${ }^{(17)}$.

In an experimental study aimed at analyzing the use of music to alleviate the physiological and behavioral responses in 13 preterm infants during the calcaneal puncture. These infants had heard lullaby songs for 10 minutes, started after the painful procedure, in intensity of about $70 \mathrm{dBA}$. The results showed that, during the Painful moment, in the Experimental Group (music) and Control Group (without music), there was an increase in heart rate and respiratory rate with values of $\mathrm{p}=0.02$ and presence of crying among neonates in both groups. During recovery, 10 minutes after puncture, heart rate and crying decreased significantly in the music group $(\mathrm{p}=0.02)$, but not in unexposed neonates ${ }^{(18)}$.

Another study evaluating 12 preterm infants with gestational age $\leq 36$ weeks, who heard a single classical music (Mozart), which was recorded and played within the incubator, close to the ear of preterm newborns, by means of a sound system, at 45 decibels, one hour after the feeding, for 15 uninterrupted minutes, twice a day, in the morning and afternoon, for three consecutive days, proved that music therapy can modify in the short term the physiological responses of hospitalized preterm infants as the heart rate decreased immediately after the second music therapy session (paired $t, p=0.002$ ), the respiratory rate decreased after the fourth and fifth sessions (paired $t, p=0.01$ and 0.03 , respectively) and oxygen saturation increased after the fifth session of music therapy $(p=0.008)^{(19)}$.

\section{Conclusion}

The preterm infants of the music group anticipated the painful stimulus in the preparation for the arterial puncture, in comparison to the value found in the Baseline moment. There were intra-subject differences within the groups, with statistically significant differences at the moment Treatment (antisepsis) and Painful moment, in favor of the Control Group (25\% glucose).

In the moments Recovery 1 (compression) and Recovery 2 (rest), in the values of the means of the NFCS scores, there was no statistically significant difference between the Experimental Group and the Control Group, thus evidencing similarity between the two intervention groups.

\section{Collaborations}

Melo GM contributed to the work design, collection, organization, interpretation of data, writing and final approval of the version to be published. Cardoso MVLML contributed to the writing of the article, critical review of the intellectual content and final approval of the version to be published. 


\section{References}

1. Hall RW, Anand KJS. Pain Management in Newborns. Clin Perinatol. 2014; 41(4):895-924.

2. Oliveira CWL, Silva JVF, Rodrigues APRA, Xavier Júnior AFS, Tenório GM. Intervenções não farmacológicas no alivio da dor em unidade de terapia intensiva neonatal. Ciênc Biol Saúde. 2016; 3(2):123-34.

3. Morais APS, Façanha SMA, Rabelo SN, Silva AVS, Queiroz MVO, Chaves EMC. Non-pharmacological measures in the pain management in newborns: nursing care. Rev Rene. 2016; 17(3):435-42.

4. Cardoso MVLML, Farias LM, Melo GM. Music and $25 \%$ glucose pain relief for the premature infant: a randomized clinical trial. Rev Latino-Am Enfermagem. 2014; 22(5):810-8.

5. Jesus LB, Bernardes DFF. Caracterização funcional da mimica facial na paralisia facial em trauma de face: relato de caso clínico. Rev CEFAC. 2012; 14(5):971-6.

6. Silva APM, Balda RCX, Guinsburg R. Reconhecimento da dor no recém-nascido por alunos de medicina, residentes de Pediatria e Neonatologia. Rev Dor. 2012; 13(1):35-44.

7. Carbajal R, Gréteau S, Arnaud C, Gued R. Douleur en néonatologie, traitements non médicamenteux. Arch Pédiatr. 2015; 22(2):217-21.

8. Bueno M, Stevens B, Camargo PP, Toma E, Krebs VL, Kimura AF. Breast milk and glucose for pain relief in preterm infants: a noninferiority randomized controlled trial. Pediatrics. 2012; 129(4):664-70.

9. Cardoso MVLML, Melo GM. Música e glicose $25 \%$ em prematuros no pré-procedimento da punção arterial: ênfase na mímica facial. Rev Eletr Enf [Internet]. 2016 [citado 2016 set. 8]; 18:1162. Disponível em: https://revistas.ufg.br/fen/ article/view/32897

10. Fialho FA, Dias IMAV, Silva LR, Santos RS, Salvador M. Tecnologias aplicadas pela enfermagem no cuidado neonatal. Rev Baiana Enferm. 2015: 29(1):23-32.
11. Falcão ACMP, Sousa ALS, Stival MM, Lima LR. Abordagem terapêutica da dor em neonatos sob cuidados intensivos: uma breve revisão. Rev Enferm Cent O Min [Internet]. 2012 [citado 2016 set. 8]: 2(1): 108-23. Disponível em: http:// www.seer.ufsj.edu.br/index.php/recom/article/ view/130/261

12. Grunau RE, Craig KD. Neonatal facial coding system revised: training manual. Vancouver: Early Human Experience Unit; 2010.

13. Bergomi P, Chieppi M, Maini A, Mugnos T, Spotti D, Tzialla $\mathrm{C}$, et al. Nonpharmacological techniques to reduce pain in preterm infants who receive heellance procedure: a randomized controlled trial. Res Theor Nurs Pract. 2014; 28(4):335-48.

14. Marcatto JO, Tavares EC, Silva YP. Benefits and limitations of the use of glucose for the treatment of pain in neonates: a literature review. Rev Bras Ter Intensiva. 2011; 23(2):228-37.

15. Dearn T, Shoemark H. The effect of maternal presence on premature infant response to recorded music. J Obstet Gynecol Neonatal Nurs. 2014; 43(3):341-50.

16. Keith DR, Weaver BS, Vogel RL. The effect of musicbased listening interventions on the volume, fat content, and caloric content of breast milkproduced by mothers of premature and critically ill infants. Adv Neonatal Care. 2012; 12(2):112-9.

17. Alipour Z, Eskandari N, Tehran HA, Hossaini SKE, Sangi S. Effects of music on physiological and behavioral responses of premature infants: a randomized controlled trial. Complement Ther Clin Pract. 2013; 19(3):128-32.

18. Tramo MJ, Lense M, Van Ness C, Kagan J, Settle MD, Cronin JH. Effects of music on physiological and behavioral indices of acute pain and stress in premature infants: clinical trial and literature review. Music Med. 2011; 3(2):72-83.

19. Silva CM, Cação JMR, Silva KCS, Marques CF, Merey LSF. Physiological responses of preterm newborn infants submitted to classical music therapy. Rev Paul Pediatr. 2013; 31(1):30-6. 